\title{
Adaptabilidade e estabilidade de genótipos de café no cultivo orgânico em Minas Gerais
}

\author{
Adaptability and stability of coffee genotypes in the organic cultivation in Minas Gerais, Brazil
}

\author{
Waldênia de Melo Moura ${ }^{I^{*}}$ Paulo César de Lima ${ }^{\mathrm{I}}$ Vanessa Schiavon Lopes $^{\mathrm{I}}$ \\ Cássio Francisco Moreira de CarvalhoI Cosme Damião Cruz ${ }^{\text {II }}$ \\ Ana Maria Cruz e Oliveira ${ }^{I I}$
}

\section{RESUMO}

\begin{abstract}
Este trabalho teve como objetivo comparar a adaptabilidade e estabilidade de cultivares de café quanto à média de produtividade anual e de biênios, pelo método de EBERHART \& RUSSEL (1996), e selecionar cultivares de café para o cultivo orgânico em Minas Gerais. Os experimentos foram conduzidos em três locais, em delineamento de blocos casualizados com trinta genótipos e três repetições. Uma análise se baseou na produtividade média anual de quatro colheitas (2005/2006, 2006/2007, 2007/2008 e 2008/2009) com o total de doze ambientes. A outra análise considerou a média de dois biênios (2005/2006 e 2006/2007; 2007/2008 e 2008/2009) com o total de seis ambientes. A análise em que se considerou a média da produtividade do biênio apresentou redução expressiva do coeficiente de variação ambiental. Por isso, foi possível identificar mais cultivares com adaptabilidade e estabilidade para o cultivo orgânico. Concluise que a análise de adaptabilidade e estabilidade com base na produtividade de biênio é mais segura para a seleção de cultivares. Considerando essa premissa, as cultivares 'Catucaí Vermelho 36/6', 'Catuaí Vermelho IAC 15' e 'Siriema 842' são indicadas somente para os ambientes favoráveis. As cultivares 'Sabiá 708', 'IBC Palma 1', 'Catucaí Amarelo 24/137', 'Oeiras MG 6851'e as linhagens H518 e H514 são indicadas para o cultivo orgânico em locais com ambientes similares aos avaliados em Minas Gerais.
\end{abstract}

Palavras-chave: Coffea arabica, interação genótipo x ambiente, agricultura orgânica.

\section{ABSTRACT}

The aim of this research was to compare the stability and adaptability of coffee cultivars in relation to the average annual yield and to the biannual yield by the method of EBERHART \& RUSSELL (1996), and select coffee cultivars for organic cultivation in Minas Gerais. The experiments were conducted at three sites in randomized block design with thirty genotypes and three replications. An analysis was based on the annual average yield of four crops (2005/2006, 2006/2007, 2007/2008 and 2008/2009) resulting in twelve environments. The other analysis considered the average of two biannual (2005/2006 and 2006/2007; 2007/2008 and 2008/2009) with a total of six environments. The analysis in which was considered that average biannual yield enabled a significant reduction in the coefficient of environmental variation. Thus, it was possible to identify cultivars with more adaptability and stability to organic cultivation. It was concluded that the analysis of stability and adaptability based on the biannual yield is more precise for selecting cultivars. Considering this premise the cultivars 'Catucai Vermelho 36/6', 'Catuaí Vermelho IAC 15' and 'Siriema 842' are promising only for favorable environments. The cultivars 'Sabia 708', 'IBC Palma 1', 'Catucaí Amarelo 24/137', 'Oeiras MG 6851' and the lines H518 and H514, stood out in organic farming in similar environments like the locations evaluated in Minas Gerais.

Key words: Coffea arabica, genotype x environment interaction, organic agriculture.

\section{INTRODUÇÃO}

Nos principais países produtores de café orgânico e agroecológico como o México, a Costa Rica e a Colômbia, e em outros países do continente Africano, a maioria das cultivares plantadas é susceptívelà ferrugem, tais como, 'Típica', 'Bourbon', 'Caturra' e 'Garnica', e, em menores proporções, as cultivares 'Catuaí' e 'Mundo Novo' (ESCAMILLA et al., 2005; PROGRAMA COOPERATIVO ICAFEMAG, 1989). Fato semelhante ocorre no Brasil, onde as lavouras de café orgânico são formadas em sua grande maioria pelas cultivares 'Catuaí Vermelho'

'Unidade Regional da Zona da Mata (UREZM), Empresa de Pesquisa Agropecuária de Minas Gerais (EPAMIG), 36570-000, Viçosa, MG, Brasil. E-mail: waldenia @epamig.ufv.br. *Autor para correspondência.

"Departamento de Biologia Geral (DBG), Universidade Federal de Viçosa (UFV), Viçosa, MG, Brasil. 
(71\%), seguidas das cultivares 'Catuaí Amarelo' (24\%) e 'Mundo Novo' (5\%), todas susceptíveis à ferrugem (MALTA et al., 2008). A maioria dessas lavouras orgânicas foram desenvolvidas por meio da conversão de lavouras convencionais, mantendose as cultivares já plantadas, o que resulta em baixas produtividades e alta incidência de doenças e pragas.

A escassez de informações sobre cultivares de café promissoras para o cultivo orgânico está associada à pouca ênfase dada à pesquisa visando esse objetivo. Vários são os entraves, destacando-se a necessidade de avaliar grande número de genótipos, o que demanda áreas extensas de plantio em diferentes locais (ambientes) por um longo período de tempo. Isso significa cerca de sete anos de pesquisa, que compreende desde a formação das mudas até a avaliação de, no mínimo, quatro colheitas, para que os resultados sejam obtidos com segurança. Além disso, requer um planejamento eficiente para a aquisição de materiais orgânicos e do plantio de espécies a serem utilizadas como adubos verdes (MOURA et al., 2005).

As condições ideais para o cultivo do café são temperaturas na faixa de $18^{\circ} \mathrm{C}$ a $23^{\circ} \mathrm{C}$, chuvas bem distribuídas durante o ano e a não ocorrência de déficit hídrico severo, suportando até $150 \mathrm{~mm}$ (CARVALHO, 2008). No Brasil, as regiões cafeeiras apresentam características ambientais bem definidas e a avaliação da interação genótipos x ambientes torna-se de grande importância no melhoramento, pois, no caso de sua existência, há possibilidades de o melhor genótipo em um ambiente não o ser em outro. Assim, as análises de adaptabilidade e estabilidade tornam-se necessárias para a identificação e recomendação de genótipos superiores em diferentes ambientes (NASCIMENTO et al., 2010). Várias são as metodologias disponíveis para esse tipo de estudo, destacando-se o método de EBERHART \& RUSSEL (1996), em que a adaptabilidade referese à capacidade de os genótipos aproveitarem vantajosamente o estímulo do ambiente e é dada em função do coeficiente de regressão $\left(\beta_{1 \mathrm{i}}\right)$; enquanto que a estabilidade refere-se à capacidade dos genótipos mostrarem um comportamento altamente previsível em função do estímulo do ambiente e é avaliada pelo componente de variância atribuído aos desvios da regressão $\left(\sigma_{\mathrm{di}}^{2}\right)$. Na cultura do café, estudos de adaptabilidade e estabilidade de cultivares têm sido realizados somente para cultivos convencionais (CORRÊA et al., 2005; BOTELHO et al., 2010; NASCIMENTO et al., 2010). Pelo fato do café ser uma cultura perene com bienalidade de produção, torna-se necessária a avaliação de, no mínimo, quatro colheitas para a recomendação de cultivares.
Entretanto, estudos de adaptabilidade e estabilidade têm sido realizados com dados de produção anual e de biênios separadamente, o que pode levar a diferentes resultados no processo de seleção. Nesse contexto, este trabalho teve como objetivo comparar a adaptabilidade e estabilidade de cultivares de café quanto à produção anual e de biênios pelo método de EBERHART \& RUSSEL (1996) e selecionar cultivares de café para o cultivo orgânico em Minas Gerais.

\section{MATERIAL E MÉTODOS}

Os experimentos foram instalados em março de 2003 e conduzidos em três localidades do estado de Minas Gerais, com diferentes altitudes e condições edafoclimáticas: o município de Araponga, com solo Latossolo Vermelho-Amarelo, A moderado, textura argilosa, com elevada acidez potencial, localizado em altitude de 1040m, com clima subtropical úmido mesotérmico, com temperaturas médias anuais mínima de $14,8^{\circ} \mathrm{C}$ e máxima de $26^{\circ} \mathrm{C}$; o município de Espera Feliz, com solo Latossolo Vermelho-Amarelo, A moderado, textura argilosa, encontra-se a $772 \mathrm{~m}$ de altitude, com clima tipicamente tropical, com temperaturas médias anuais variando entre a mínima de $12,8^{\circ} \mathrm{C}$ e a máxima de $25,3^{\circ} \mathrm{C}$; o município de Tombos, com solo Argissolo VermelhoAmarelo, A fraco, textura muito argilosa, encontra-se a $620 \mathrm{~m}$ de altitude com clima tropical quente, com sete meses de défice hídrico e temperatura média anual mínima de $12,6^{\circ} \mathrm{C}$ e máxima de $30,8^{\circ} \mathrm{C}$

$\mathrm{O}$ delineamento experimental utilizado em todos os municípios foi em blocos casualizados, com 30 genótipos (cultivares e linhagens) e três repetições. As parcelas foram constituídas por 10 plantas, em uma única linha, sendo adotados, para cultivares de porte baixo, espaçamentos entre plantas e fileiras de $0,5 \times 4,0 \mathrm{~m}$, respectivamente, e de $0,8 \times 4,0 \mathrm{~m}$, para cultivares de porte alto. Utilizaram-se as seguintes cultivares e linhagens (CARVALHO, 2008): porte baixo e resistente à ferrugem - 'Paraíso MG $\mathrm{H}$ 419-1', 'Obatã IAC 1669-20', 'Tupi IAC 1669-33', 'IAPAR 59', 'Acauã' e as linhagens H 514 e H 518; porte baixo e moderadamente resistente à ferrugem - 'Catucaí Amarelo 24/137', 'Catucaí Vermelho 36/6', 'Catucaí-Açu' e 'Catucaí 785/ 15', 'IBC Palma 1', 'IBC Palma 2', 'Oeiras MG 685' e 'Sabiá 708'; porte baixo, moderadamente resistente à ferrugem e resistente ao bicho-mineiro - 'Siriema 842'; porte alto e moderadamente resistente à ferrugem - 'Canário', 'Icatu Precoce IAC 3282', 'Icatu Vermelho IAC 4045' e 'Icatu Amarelo IAC 2944'; porte baixo e suscetível 
à ferrugem - 'Rubi MG 1192', 'Topázio MG 1190', 'Ouro Verde IAC H 5010 - 5', 'Catuaí Amarelo IAC 62', 'Catuaí Vermelho IAC 15', 'Caturra Amarelo IAC 476', 'Caturra Vermelho IAC 477'; porte alto e suscetível à ferrugem - 'Acaiá Cerrado MG 1474', 'Mundo Novo IAC 379-19' e 'Maragogipe'. As correções das necessidades de calagem e de adubações de plantio e cobertura nas áreas experimentais foram realizadas com base nas análises de solo e conforme as Recomendações Para o Uso de Corretivos e Fertilizantes em Minas Gerais (RIBEIRO et al.,1999), para a cultura do café. Foram realizadas calagem com calcário dolomítico e adubações com esterco bovino, termofosfato, e sulfato duplo de potássio e magnésio, produtos permitidos para o cultivo orgânico. Durante a condução dos experimentos, as adubações de cobertura anual foram realizadas conforme descrito em MOURA et al. (2005). Como fonte de nitrogênio, foi utilizada a torta de mamona, complementada com adubos verdes (Crotalaria juncea e Arachis pintoi), ambas as leguminosas foram cultivadas nas entrelinhas dos cafeeiros e cortadas no início das florações. Como fontes de fósforo e de potássio, durante a produção, foram utilizadas as mesmas do plantio e as adubações foliares foram realizadas anualmente utilizando o biofertilizante supermagro. O controle de plantas daninhas foi realizado com capinas e com roçadas periódicas e os resíduos utilizados como cobertura morta.

As avaliações de produtividade foram efetuadas em quatro colheitas consecutivas, medida em litros e convertida para sacas $(60 \mathrm{~kg})$ de café beneficiado/ ha/ano, nas safras 2005/2006, 2006/2007, 2007/2008 e 2008/2009 em três locais (Araponga, Espera Feliz e Tombos), totalizando 12 ambientes. Utilizaram-se também os dados de médias dos biênios, sendo o biênio 1 (safras 2005/2006 e 2006/2007) e biênio 2 (safras 2007/2008 e 2008/2009) nas mesmas localidades, totalizando 6 ambientes. Foram realizadas análises de variância conjunta, em blocos casualizados, com interação tripla Genótipos x Locais x Anos e Genótipos $\mathrm{x}$ Locais x Biênios. As análises de adaptabilidade e estabilidade foram realizadas utilizando a metodologia de EBERHART \& RUSSELL (1966). Esse método baseiase no seguinte modelo de regressão linear: $\mathrm{Y}_{\mathrm{ij}}=\beta_{\mathrm{oi}}+\beta_{\mathrm{li}}$ $\mathrm{I}_{\mathrm{j}}+\delta_{\mathrm{ij}}+\bar{\varepsilon}_{\mathrm{ij}}$, em que: $\mathrm{Y}_{\mathrm{ij}}=$ média da cultivar i no ambiente $\mathrm{j} ; \beta_{\mathrm{oi}}=$ média geral da cultivar $\mathrm{i} ; \beta_{\mathrm{li}}=$ coeficiente de regressão linear, que mede a resposta da i-ésima cultivar à variação do ambiente; $\mathrm{I}=$ índice ambiental codificado; $\delta_{\mathrm{ij}}=$ desvio da regressão; e $\varepsilon$ e $\bar{\varepsilon}_{\mathrm{ij}}=$ erro experimental médio. Os coeficientes de regressão de cada genótipo em relação ao índice ambiental $\left(\beta_{1 \mathrm{i}}\right)$ e os desvios desta regressão $\left(\sigma_{\mathrm{di}}^{2}\right)$ proporcionam estimativas de parâmetros de adaptabilidade e estabilidade, respectivamente. São considerados de adaptabilidade geral os genótipos que apresentarem $\beta_{1 \mathrm{i}}=1$; adaptabilidade específica a ambientes favoráveis, aqueles com $\beta_{1 \mathrm{i}}>1$; e adaptabilidade específica a ambientes desfavoráveis, aqueles com $\beta_{1 \mathrm{i}}<1$. A estabilidade está relacionada com a previsibilidade de comportamento, dada pelo componente de variância devido aos desvios da regressão $\left(\sigma_{\mathrm{di}}^{2}\right)$, sendo estáveis (previsíveis) quando $\sigma_{\mathrm{di}}^{2}=0$ e pouco estáveis ou instáveis (imprevisíveis) quando $\sigma_{\mathrm{di}}^{2} \neq 0$. A variedade considerada "ideal" deve apresentar média elevada, coeficiente de regressão igual ou próximo da unidade $\left(\beta_{1 \mathrm{i}}=1\right)$ e desvios da regressão não diferindo significativamente de zero $\left(\sigma_{\mathrm{di}}^{2}=0\right)$. As análises estatísticas foram realizadas utilizando o programa Genes (CRUZ, 2006).

\section{RESULTADOS E DISCUSSÃO}

A produtividade apresentou interações significativas para genótipo $\mathrm{x}$ ano, genótipo $\mathrm{x}$ locais, genótipos x anos x locais e genótipos x biênios (Tabela 1). Isso implica que o comportamento dos genótipos foi influenciado pelas condições ambientais, justificando a utilização de metodologias que possam classificar os genótipos de acordo com sua adaptabilidade e estabilidade. Essa interação é influenciada por dois componentes ambientais, os previsíveis, como as práticas agronômicas e o tipo de solo, e os não previsíveis, como as oscilações de temperaturas, ocorrência de doenças e pragas e intempéries climáticas (VENCOVSKY \& BARRICA, 1992). A média geral da produtividade foi de aproximadamente 28 sacas de café beneficiado/ha/ano, (Tabela 2), superando as produtividades observadas em sistemas orgânicos sombreado e a pleno sol (RICCI et al., 2006), e semelhantes às constatadas por SANTOS et al. (2008) e LOPES \& FERRAZ (2009).

Análise de adaptabilidade e estabilidade com base na produtividade anual de quatro colheitas

O município de Espera Feliz apresentou o maior número de ambientes favoráveis, ou seja, $\mathrm{Ij}$ positivo, (Tabela 2), devido às melhores condições edafoclimáticas, não sendo evidenciados os efeitos da bienalidade de produção. Ao contrário, no município de Araponga, esse fenômeno foi mais evidente (Tabela 3), provavelmente, devido aos efeitos das temperaturas mais baixas associadas com a elevada acidez potencial do solo. Essa alternância de produção é própria da natureza fisiológica do cafeeiro, que necessita vegetar em um ano para produzir bem no ano seguinte (RENA \& MAESTRI, 1985). A bienalidade de produção é decorrente da redução das reservas das plantas em anos 
Tabela 1 - Resumos das análises de variância conjunta para a produtividade de café beneficiado, em sacas de $60 \mathrm{~kg} \mathrm{ha}^{-1}$ ano ${ }^{-1}$ e biênio de 30 cultivares de café cultivadas em sistema orgânico em Minas Gerais, 2012.

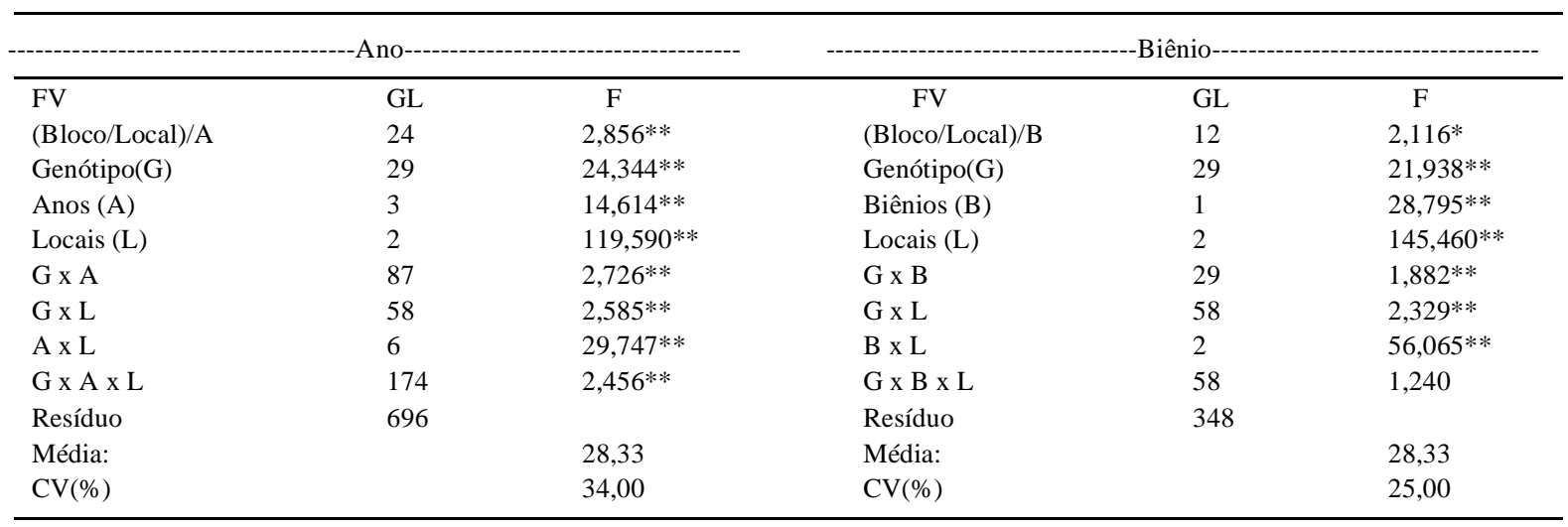

** Significativa a $1 \%$ de probabilidade pelo teste $\mathrm{F}$.

* Significativo a $5 \%$ de probabilidade pelo teste $\mathrm{F}$.

de safra com altas produtividades e, consequentemente, menor crescimento dos ramos plagiotrópicos, afetando a produção no ano seguinte (DAMATTA et al., 2007; SILVA et al., 2008). Essa característica independe do ano e é altamente influenciada pelas condições ambientais e pelo manejo da lavoura. No município de Tombos, todos os anos foram desfavoráveis (Tabela 3), o que pode ser atribuído a altos défices hídricos $(116,7 \mathrm{~mm})$ da região (CALDERANO FILHO et al., 2005). Também as temperaturas mais elevadas e as características físicas do solo menos favoráveis contribuíram para as menores produtividades. Segundo MURAKAMI et al. (2004), a simples classificação de ambientes em favoráveis e desfavoráveis pode não refletir a existência de divergências ambientais, mas dá uma ideia de como os genótipos se comportarão frente às variações ambientais. A maioria das cultivares apresentou adaptabilidade geral $\left(\beta_{1 \mathrm{i}}=1\right)$, porém com alto número de cultivares com instabilidade de produção $\left(\sigma^{2}{ }_{\mathrm{di}} \neq 0\right)$ (Tabela 3$)$, fato indesejável para o processo seletivo, por apresentarem comportamentos imprevisíveis. Dentre esses genótipos, apenas a linhagem H518 e a cultivar 'Oeiras MG 6851' foram estáveis e produtivas. Quatro cultivares apresentaram adaptabilidade a ambientes favoráveis, sendo duas com potencial para o cultivo orgânico. Observaram-se também cultivares com adaptabilidade

Tabela 2 - Estimativas das médias de produtividade em sacas de $60 \mathrm{~kg} \mathrm{ha}^{-1}$ ano $^{-1}$ e biênio (Prod), e dos índices de ambientes (Ij) pela metodologia de EBERHART \& RUSSELL.

\begin{tabular}{lccccc}
\hline Ambiente / Ano & Média Prod & $\mathrm{Ij}$ & \multicolumn{2}{c}{ Ambiente / Bienio } & Média Prod \\
\hline Araponga 2006 & 30,17 & 1.8375 & Araponga 2005/2006 e 2006/2007 & 27,09 & -1.2388 \\
Espera Feliz 2006 & 25,41 & -2.9232 & Espera Feliz 2005/2006 e 2006/2007 & 29,67 & 1.336 \\
Tombos 2006 & 25,35 & -2.9801 & Tombos 2005/2006 e 2006/2007 & 20,96 & 24,13 \\
Araponga 2007 & 24,01 & -4.315 & Araponga 2007/2008 e 2008/2009 & 47,98 \\
Espera Feliz 2007 & 33,92 & 5.5956 & Espera Feliz 2007/2008 e 2008/2009 & 20,14 \\
Tombos 2007 & 16,58 & -11.7536 & Tombos 2007/2008 e 2008/2009 & 19.6516 \\
Araponga 2008 & 31,80 & 3.4699 & & -8.1875 \\
Espera Feliz 2008 & 53,72 & 25.3885 & & \\
Tombos 2008 & 15,67 & -12.6555 & & \\
Araponga 2009 & 16,47 & -11.8583 & & \\
Espera Feliz 2009 & 42,24 & 13.9146 & & \\
Tombos 2009 & 24,61 & -3.7205 & & & \\
Média Geral da Produtividade & 28,33 & & & \\
\hline
\end{tabular}

Ij positivo = ambientes favoráveis

Ij negativo = ambientes desfavoráveis 
Tabela 3 - Estimativa dos parâmetros de adaptabilidade e estabilidade pelo método de EBERHART E RUSSELL (1966), para produtividade de café beneficiado, em sacas de $60 \mathrm{~kg} \mathrm{ha}^{-1} \mathrm{ano}^{-1}$ e biênio.

\begin{tabular}{|c|c|c|c|c|c|c|c|}
\hline \multirow{2}{*}{ CULTIVARES } & \multirow{2}{*}{$\operatorname{MÉDIA}\left(ß_{0}\right)$} & \multicolumn{3}{|c|}{ 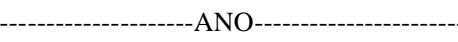 } & \multicolumn{3}{|c|}{---------------BIÊNIO--- } \\
\hline & & $B_{1 \mathrm{i}}^{2 /}$ & $\sigma_{\mathrm{di}}^{23 /}$ & $\mathrm{R}^{2}(\%)$ & $B_{1}^{2 /}$ & $\sigma_{\mathrm{di}}^{2}{ }^{3 /}$ & $\mathrm{R}^{2}(\%)$ \\
\hline 'Sabiá 708' & 42,64 & $1,18 \mathrm{~ns}$ & $78,12 * *$ & 63,69 & $1,03 \mathrm{~ns}$ & $-10,53 \mathrm{~ns}$ & 95,37 \\
\hline 'H518' & 41,79 & $1,09 \mathrm{~ns}$ & $18,33 \mathrm{~ns}$ & 76,73 & $1,04 \mathrm{~ns}$ & $-8,09 \mathrm{~ns}$ & 93,95 \\
\hline 'Catucaí Amarelo24/137' & 40,89 & $1,52 * *$ & $49,28 * *$ & 79,73 & $1,33 \mathrm{~ns}$ & $12,13 \mathrm{~ns}$ & 88,77 \\
\hline 'IBC Palma 1' & 40,75 & $1,47 * *$ & $36,39 *$ & 81,34 & $1,26 \mathrm{~ns}$ & $-6,36 n s$ & 95,06 \\
\hline 'Catucaí Vermelho 36/6' & 38,47 & $1,83^{* *} *$ & $-3,87 \mathrm{~ns}$ & 94,35 & $1,72 * *$ & $-7,63 \mathrm{~ns}$ & 97,58 \\
\hline 'Paraiso MG H 419-1' & 37,34 & $1,46^{* *}$ & $33,86^{*}$ & 81,84 & $1,58 * *$ & $30,82^{*}$ & 87,30 \\
\hline 'Catuaí Vermelho IAC 15' & 34,41 & $1,21 \mathrm{~ns}$ & $67,64 * *$ & 67,05 & $1,36^{*}$ & $-4,60 \mathrm{~ns}$ & 95,08 \\
\hline 'Oeiras MG 6851' & 33,32 & $1,13 \mathrm{~ns}$ & $-18,75 n s$ & 93,31 & $1,08 \mathrm{~ns}$ & $-14,31 \mathrm{~ns}$ & 98,08 \\
\hline 'H 514' & 32,39 & $1,19 \mathrm{~ns}$ & $61,86^{* *}$ & 67,55 & $1,09 \mathrm{~ns}$ & $1,01 \mathrm{~ns}$ & 89,50 \\
\hline 'Siriema 842' & 31,34 & $0,79 \mathrm{~ns}$ & $30,49 *$ & 58,37 & $0,53 * *$ & $-8,84 \mathrm{~ns}$ & 81,30 \\
\hline 'IBC Palma 2' & 30,25 & $0,53 * *$ & $8,92 \mathrm{~ns}$ & 48,89 & $0,52 * *$ & $3,88 \mathrm{~ns}$ & 62,92 \\
\hline 'Ouro Verde' & 29,87 & $0,65^{*}$ & $128,62 * *$ & 26,48 & $0,77 \mathrm{~ns}$ & $-2,30 \mathrm{~ns}$ & 83,93 \\
\hline 'Tupi IAC 1669-33' & 28,71 & $0,92 \mathrm{~ns}$ & $72,30 * *$ & 52,91 & $0,68 \mathrm{~ns}$ & $28,36^{*}$ & 57,08 \\
\hline 'Obatã IAC 1669-20' & 27,9 & $1,19 \mathrm{~ns}$ & $50,63 * *$ & 70,49 & $1,16 \mathrm{~ns}$ & $-6,74 n s$ & 94,36 \\
\hline 'Catucaí 785/15' & 27,08 & $0,96 \mathrm{~ns}$ & $5,18 \mathrm{~ns}$ & 77,46 & $0,93 \mathrm{~ns}$ & $2,71 \mathrm{~ns}$ & 85,04 \\
\hline 'Rubi MG 1192' & 27,04 & $1,02 \mathrm{~ns}$ & $2,40 \mathrm{~ns}$ & 80,80 & $0,96 \mathrm{~ns}$ & $1,66 \mathrm{~ns}$ & 86,62 \\
\hline 'Canário' & 26,19 & $0,55^{* *}$ & $11,22 \mathrm{~ns}$ & 49,01 & $0,37 * *$ & $10,88 \mathrm{~ns}$ & 39,64 \\
\hline 'Icatu Amarelo IAC 2944' & 26,13 & $0,88 \mathrm{~ns}$ & $37,04 *$ & 61,00 & $0,81 \mathrm{~ns}$ & $44,96^{* *}$ & 57,98 \\
\hline 'Catuaí Amarelo IAC 62' & 26,04 & $0,39 * *$ & $59,00 * *$ & 18,99 & $0,36^{* *}$ & $-2,80 \mathrm{~ns}$ & 54,77 \\
\hline 'Icatu Precoce IAC 3282' & 25,07 & $1,28 \mathrm{~ns}$ & $34,51 *$ & 77,46 & $1,31 \mathrm{~ns}$ & $35,71^{*}$ & 81,07 \\
\hline 'Catucaí Açu' & 24,89 & $1,12 \mathrm{~ns}$ & $146,04 * *$ & 49,13 & $1,07 \mathrm{~ns}$ & $42,44^{* *}$ & 71,86 \\
\hline 'Topázio MG 1190' & 24,85 & $0,96 \mathrm{~ns}$ & $67,12 * *$ & 56,29 & $1,24 \mathrm{~ns}$ & $34,62 *$ & 79,65 \\
\hline 'Caturra Amarelo IAC 476' & 22,96 & $1,04 \mathrm{~ns}$ & $16,57 \mathrm{~ns}$ & 75,65 & $1,19 \mathrm{~ns}$ & $23,60 \mathrm{~ns}$ & 82,02 \\
\hline 'IAPAR 59' & 22,93 & $1,17 \mathrm{~ns}$ & $-2,91 \mathrm{~ns}$ & 86,89 & $1,08 \mathrm{~ns}$ & $-3,00 \mathrm{~ns}$ & 91,48 \\
\hline 'Acauã' & 22,86 & $0,64 *$ & $11,63 \mathrm{~ns}$ & 56,53 & $0,49 * *$ & $11,48 \mathrm{~ns}$ & 53,28 \\
\hline 'Icatu Vermelho IAC 4045' & 20,13 & $1,02 \mathrm{~ns}$ & $-19,09 \mathrm{~ns}$ & 92,12 & $1,11 \mathrm{~ns}$ & $-13,57 \mathrm{~ns}$ & 97,74 \\
\hline 'Mundo Novo IAC 379-19' & 19,40 & $0,62 *$ & $35,63^{*}$ & 44,43 & $0,85 \mathrm{~ns}$ & $0,52 \mathrm{~ns}$ & 84,27 \\
\hline 'Caturra Vermelho IAC 477' & 16,80 & $0,82 \mathrm{~ns}$ & $23,20 \mathrm{~ns}$ & 63,18 & $1,00 \mathrm{~ns}$ & $-1,37 \mathrm{~ns}$ & 89,26 \\
\hline 'Acaiá Cerrado MG 1474' & 16,66 & $0,74 \mathrm{~ns}$ & $72,79 * *$ & 42,26 & $1,10 \mathrm{~ns}$ & $7,36 \mathrm{~ns}$ & 86,69 \\
\hline 'Maragogipe' & 10,79 & $0,64 *$ & $59,43 * *$ & 38,06 & $0,92 \mathrm{~ns}$ & $-5,92 \mathrm{~ns}$ & 90,75 \\
\hline 'Média Geral' & 28,33 & & & & & & \\
\hline
\end{tabular}

${ }^{1 /}$ Médias com as mesmas letras na coluna não diferem estatisticamente pelo teste de Scott-Knott ao nível de $5 \%$ de probabilidade; ${ }^{2 /} \mathrm{H}_{\mathrm{o}}=\beta_{1 \mathrm{i}}$ $=1 .{ }^{3 /} \mathrm{H}_{\mathrm{o}}=\sigma_{\mathrm{di}}^{2}=0 .{ }^{\mathrm{ns}}$ Não significativo, $*$ e $* *$ significativo a 5 e $1 \%$ de probabilidade, respectivamente, pelo teste $\mathrm{t}$ de Student.

a ambientes desfavoráveis, mas somente a cultivar 'IBC Palma 2' foi produtiva e estável (Tabela 3).

Com relação ao grupo Catuaí que é amplamente cultivado no país, em decorrência da elevada adaptação a diversas regiões cafeeiras, a cultivar 'Catuaí Vermelho IAC 15' apresentou adaptabilidade geral, enquanto que a 'Catuaí Amarelo IAC 62' apresentou adaptação específica a ambientes desfavoráveis, entretanto, ambas as cultivares foram instáveis (Tabela 3). Essas cultivares apresentaram adaptabilidade somente a ambientes favoráveis, em sistemas convencionais no Sul de Minas (BARTHOLO et al., 1999).

Entre os dez genótipos mais produtivos, as cultivares 'Sabiá 708', 'Catuaí Vermelho IAC 15',
'Oeiras MG 6851', 'Siriema 842' e as linhagens H514 e H518 apresentaram adaptabilidade geral $\left(\beta_{1 \mathrm{i}}=1\right)$, entretanto, apenas a linhagem H518 e a cultivar 'Oeiras MG 6851' mostraram-se estáveis $\left(\sigma_{\mathrm{di}}^{2}=0\right)$, ou seja, com comportamentos previsíveis, apresentando potencial para o cultivo orgânico (Tabela 3). Já as cultivares 'Catucaí Amarelo 24/137', 'IBC Palma 1', 'Paraíso MG H 419-1' e 'Catucaí Vermelho 36/6' apresentaram adaptação específica a ambientes favoráveis $\left(\beta_{1 i}>1\right)$, entretanto, somente a última cultivar apresentou alta estabilidade $\left(\sigma_{\mathrm{di}}^{2}=0\right)$, (Tabela 3$)$.

Análise de adaptabilidade e estabilidade com base na produtividade da média do biênio 
Assim como observado para a análise anterior, os municípios de Espera Feliz e Tombos novamente apresentaram-se como ambientes favoráveis e desfavoráveis, respectivamente, (Tabela 2). Entretanto, no município de Araponga, as produtividades nos anos favoráveis não superaram a redução desta nos anos desfavoráveis, afetando de forma negativa a média do biênio, classificando-o como desfavorável (Tabela 2). Observou-se que entre os dez genótipos mais produtivos, as cultivares 'Sabiá 708', 'IBC Palma 1', 'Catucaí Amarelo 24/137', 'Oeiras MG 6851' e as linhagens H518 e H514 apresentaram adaptação $\left(\beta_{1 \mathrm{i}}=1\right)$ e estabilidade de produção $\left(\sigma_{\mathrm{di}}^{2}=0\right)$ para o cultivo orgânico (Tabela 3$)$, ou seja, com comportamentos previsíveis, e podem ser indicadas para sistemas de cultivos similares a esse. Vale ressaltar que todos esses genótipos apresentam resistência genética à ferrugem. Por outro lado, as cultivares, 'Catucaí Vermelho 36/6', 'Siriema 842' e 'Catuaí Vermelho IAC 15' podem ser recomendadas somente para os ambientes favoráveis (Tabela 3), onde haja investimento em tecnologias, visto que a última cultivar é susceptível à ferrugem. Comportamento semelhante foi observado por BOTELHO et al. (2010), para essa cultivar, avaliada em sistema de cultivo convencional na região de Três Pontas, Campos Altos e Capelinha, no estado de Minas Gerais, utilizando a metodologia de Annicchiarico. Esses resultados sugerem que essa cultivar seja muito exigente no manejo da adubação, independentemente do sistema de cultivo.

Com relação às cultivares de porte alto, 'Icatu Amarelo IAC 2944' e 'Icatu Precoce IAC 3282' apresentaram baixas produtividades, associadas com ampla adaptabilidade e instabilidade de produção (Tabela 3). Resultados semelhantes foram observados por CORREA et al. (2005), utilizando as metodologias de Annicchiarico e Lin \& Binns, para cultivos convencionais. Isso sugere que os ambientes testados não favoreceram o desempenho dessas cultivares. Ao contrário do constatado por CORREA et al. (2005), a cultivar 'Icatu Vermelho IAC 4045' apresentou baixa produtividade, porém manteve a adaptabilidade e a estabilidade de produção (Tabela 3). Já as cultivares 'Mundo Novo' e 'Acaiá Cerrado', embora tenham apresentado adaptação ao cultivo orgânico, foram pouco produtivas (Tabela 3). Cultivares também classificadas por CORRÊA et al. (2005) e BOTELHO et al. (2010) foram consideradas como as de piores desempenhos por meio da metodologia de Annicchiarico e Lin \& Binns. As cultivares 'Rubi MG 1192' e 'IAPAR 59', apesar de não estarem entre as mais produtivas, apresentaram-se adaptadas ao cultivo orgânico
(Tabela 3). BOTELHO et al. (2010) constatou baixas produtividades para essas cultivares no Sul de Minas, porém com comportamento oposto quanto à adaptabilidade e estabilidade de produção. Essas diferenças são esperadas em virtude das diversidades de ambientes e dos sistemas de cultivos utilizados. Por outro lado, a cultivar 'Topázio' apresentou ampla adaptabilidade, mas com instabilidade de produção (Tabela 3), diferente do observado por BOTELHO et al. (2010), em que essa cultivar foi recomendada apenas para ambientes desfavoráveis no Sul de Minas Gerais.

Comparando-se as estimativas dos parâmetros de adaptabilidade e estabilidade discutidos acima, foi constatado que, na análise com dados de produtividade médias anuais de quatro colheitas, as cultivares apresentaram grande instabilidade de produção, ao contrário dos resultados da análise com base na média dos biênios, que promoveu a estabilidade na produtividade. Nessa condição, houve aumento na quantidade de cultivares classificadas com adaptabilidade geral, com estabilidade de produção e indicadas para ambientes favoráveis. Além disso, houve acréscimo de três vezes mais no número de cultivares recomendadas para o cultivo orgânico, quando comparado com as estimativas dos parâmetros de adaptabilidade e estabilidade, considerando a média de quatro colheitas (Tabela 3). A combinação das colheitas em biênios contribuiu para reduzir o coeficiente de variação ambiental (Tabela 1), melhorando a precisão experimental, fato também constatado por BONOMO et al. (2004). De acordo com CRUZ et al. (2004), avaliações com base em médias de ambientes, como no caso biênio, diminuem a variância ambiental, e a variância genotípica é consumida pela interação genótipo $\mathrm{x}$ ambiente, fato observado neste trabalho (Tabela 1), tornando o processo mais eficiente em termos de seleção.

\section{CONCLUSÃO}

As estimativas dos parâmetros de adaptabilidade e de estabilidade com base na produtividade dos biênios são mais eficientes para a seleção de cultivares. Nessa condição, as cultivares 'Catucaí Vermelho 36/6', 'Catuaí Vermelho IAC 15' e 'Siriema 842' são promissoras somente para os ambientes favoráveis. As cultivares 'Sabiá 708', 'IBC Palma 1', 'Catucaí Amarelo 24/137', 'Oeiras MG 6851' e as linhagens H518 e H514 são amplamente adaptadas, estáveis e produtivas e indicadas para ambientes similares aos avaliados para o cultivo orgânico em Minas Gerais. 


\section{AGRADECIMENTOS}

Ao Conselho Nacional de Desenvolvimento Científico e Tecnológico ( $\mathrm{CNPq}$ ), ao Consórcio Brasileiro de Pesquisa e Desenvolvimento do Café (CBP\&D-Café) e à Fundação de Amparo a Pesquisa do Estado de Minas Gerais (FAPEMIG), pelo apoio financeiro à pesquisa e pelas bolsas concedidas aos autores.

\section{REFERÊNCIAS}

BARTHOLO, G. F. et al. Estabilidade fenotípica de produção de progênies das cultivares 'Catuaí Amarelo' e 'Catuaí Vermelho', de Coffea arabica, Poços de Caldas, MG. In: SIMPÓSIO DE PESQUISA DOS CAFÉS DO BRASIL, Brasília, DF. Anais... Brasília: Embrapa - Café, 2000. v.1, p.544-546.

BONOMO, P. et al. Avaliação de progênies obtidas de cruzamentos de descendentes do híbrido de Timor com as cultivares 'Catuaí Vermelho' e 'Catuaí Amarelo'. Bragantia, v.63, n.2, p.207219, 2004. Disponível em: <http://dx.doi.org/10.1590/S000687052004000200006>. Acesso: em 5 out. 2012.doi: 10.1590/ S0006-87052004000200006.

BOTELHO, C.E. et al. Adaptabilidade e estabilidade fenotípica de cultivares de café arábica em Minas Gerais. PesquisaAgropecuária Brasileira, v.45, n.12, p.1404-1411, 2010. Disponível em: <http:// dx.doi.org/10.1590/S0100-204X2010001200010>. Acesso em: 18 dez. 2012. doi: 10.1590/S0100-204X2010001200010.

CALDERANO FILHO, B. . et al. Uso e cobertura das terras da área do entorno do reservatório da usina hidrelétrica de Tombos, no Estado de Minas Gerais. Rio de Janeiro: Embrapa solo, 2005. 58p. (Boletim de Pesquisa e Desenvolvimento).

CARVALHO, C.H.S. Cultivares de café: origem, características e recomendações. Brasília: Embrapa-Café, 2008. 334p.

CORRÊA, L.V.T. et al. Comportamento de progênies de cafeeiro Icatu. Ciência Agrotécnica, v.30, n.4, p.618-622, 2005. Disponível em: <http://dx.doi.org/10.1590/S1413-70542 006000400004>. Acesso em: 26 nov. 2012. doi: 10.1590/S141370542006000400004

CRUZ, C.D. Programa Genes-Biometria. Viçosa: UFV, 2006. 382p.

CRUZ, C.D. et al. Modelos biométricos aplicados ao melhoramento genético. Viçosa: UFV, 2004. V.1, 193p.

DAMATTA, F.M. et al. Ecophysiology of coffee growth and production. Brazilian Journal of Plant Physiology, v.19, p.485510, 2007. Disponível em: <http://dx.doi.org/10.1590/S167704202007000400014>. Acesso em: 8 dez. 2012. doi: 10.1590/ S1677-04202007000400014.

EBERHART, A.S.; RUSSEL, W.A. Stability parameters for comparing varieties. Crop Science, v.6, n.1, p.36-40, 1996 Disponível em: <https://www.crops.org/publications/cs/abstra cts/6/1/CS0060010036>. Acesso em: 17 nov. 2012. doi: 10.2135/ cropsci1966.0011183X000600010011x.

ESCAMILLA, E.P. et al. El agroecosistema café orgánico en México. Manejo integrado de plagas y agroecología, n.76, p.05$16,2005$.
LOPES, P.R.; FERRAZ, J.M.G. Caracterização do manejo de agroecossistemas cafeeiros convencional, organo-mineral, orgânico e agroflorestal em Minas Gerais. Revista Brasileira de Agroecologia, v.4, n.2, p.805-809, 2009

MALTA, M.R. et al. Caracterização de lavouras cafeeiras cultivadas sob o sistema orgânico no sul de Minas Gerais. Ciência Agrotécnica, v.32, n.5, p.1402-1407, 2008. Disponível em: <http://www.scielo.br/scielo.php?script=sci_arttext\&pid=S141370542008000500007\&lang=pt $>$. Acesso em: 8 dez. 2012. doi: http://dx.doi.org/10.1590/S1413-70542008000500007.

MENDES, A.N.G. et al. Métodos de avaliação de progênies de Coffea arabica, cultivar 'Catuaí'. Ciência e Agrotecnologia, v.20, n.3, p.315-322, 1996.

MOURA, W.M. et al. Pesquisas em sistemas agroecológicos e orgânicos da cafeicultura familiar na Zona da Mata Mineira. Informe Agropecuário, v.26, ed. especial, p.46-75, 2005.

MURAKAMI, D.M. et al. Considerações sobre duas metodologias de análises de estabilidade e adaptabilidade. Ciência Rural, v.34, n.1, p.71-78, 2004. Disponível em: <http://www.scielo.br/ scielo.php?script=sci_arttext\&pid=S0103-84782004000100011>. Acessoem: 19 out. 2012. doi: 10.1590/S0103-84782004000100011.

NASCIMENTO, M, et al. Adaptabilidade e estabilidade via regressão não paramétrica em genótipos da café. Pesquisa Agropecuária Brasileira, v.45, n.1, p.41-48, 2010. Disponível em: <http://dx.doi.org/10.1590/S0100-204X2010000100006>. Acesso em: 22 nov. 2012. doi: 10.1590/S0100-204X2010000100006.

RICCI, M.S.F. et al. Cultivo orgânico de cultivares de café a pleno sol e sombreado. Pesquisa Agropecuária Brasileira, v.41, n.4, p.569-575, 2006. Disponível em: <http://dx.doi.org/10.1590/ S0100-204X2006000400004>. Acesso em: 2 dez. 2012. doi: 10.1590/S0100-204X2006000400004

PROGRAMA COOPERATIVO ICAFE-MAG. Manual de recomendaciones para el cultivo del café. San José: Lítografia e Imprenta L IL, 1989. 122p.

RENA, A.B.; MAESTRI, M. Fisiologia do cafeeiro. Informe Agropecuário, v.11, n.126, p.26-40, 1985.

RIBEIRO, A.C. et al. Recomendações para uso de corretivos e fertilizantes em Minas Gerais: $5^{\text {a }}$ aproximação. Viçosa: CFSEMG, 1999. 359p.

SANTOS, F.S. et al. Adubação orgânica, nutrição e progresso de cercosporiose e ferrugem do cafeeiro. Pesquisa Agropecuária Brasileira, v.43, n.7, p.783-791, 2008. Disponível em: <http:// dx.doi.org/10.1590/S0100-204X2008000700001>. Acesso em: 10 out 2012. doi: 10.1590/S0100-204X2008000700001.

SILVA, C.A. et al. Productivity and yield of coffee plant under irrigation levels. Pesquisa Agropecuária Brasileira, v.43, p.387394, 2008. Disponível em: <http://dx.doi.org/10.1590/S0100204X2008000300014>. Acesso em: 2 dez 2012. doi: 10.1590/ S0100-204X2008000300014.

VENCOVSKY, R.; BARRIGA, P. Genética biométrica aplicada no fitomelhoramento. Ribeirão Preto: Sociedade Brasileira de Genética,1992. 496p. 